NASA/TM-2001-211096

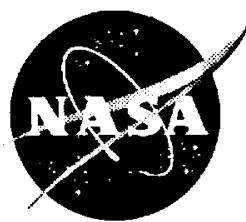

\title{
Pressure Probe Designs for Dynamic Pressure Measurements in a Supersonic Flow Field
}

\author{
A. Robert Porro \\ Glenn Research Center, Cleveland, Ohio
}


Since its founding, NASA has been dedicated to the advancement of aeronautics and space science. The NASA Scientific and Technical Information (STI) Program Office plays a key part in helping NASA maintain this important role.

The NASA STI Program Office is operated by Langley Research Center, the Lead Center for NASA's scientific and technical information. The NASA STI Program Office provides access to the NASA STI Database, the largest collection of aeronautical and space science STI in the world. The Program Office is also NASA's institutional mechanism for disseminating the results of its research and development activities. These results are published by NASA in the NASA STI Report Series, which includes the following report types:

- TECHNICAL PUBLICATION. Reports of completed research or a major significant phase of research that present the results of NASA programs and include extensive data or theoretical analysis. Includes compilations of significant scientific and technical data and information deemed to be of continuing reference value. NASA's counterpart of peerreviewed formal professional papers but has less stringent limitations on manuscript length and extent of graphic presentations.

- TECHNICAL MEMORANDUM. Scientific and technical findings that are preliminary or of specialized interest, e.g., quick release reports, working papers, and bibliographies that contain minimal annotation. Does not contain extensive analysis.

- CONTRACTOR REPORT. Scientific and technical findings by NASA-sponsored contractors and grantees.
- CONFERENCE PUBLICATION. Collected papers from scientific and technical conferences, symposia, seminars, or other meetings sponsored or cosponsored by NASA.

- SPECIAL PUBLICATION. Scientific, technical, or historical information from NASA programs, projects, and missions, often concerned with subjects having substantial public interest.

- TECHNICAL TRANSLATION. Englishlanguage translations of foreign scientific and technical material pertinent to NASA's mission.

Specialized services that complement the STI Program Office's diverse offerings include creating custom thesauri, building customized data bases, organizing and publishing research results ... even providing videos.

For more information about the NASA STI Program Office, see the following:

- Access the NASA STI Program Home Page at http://www.sti.nasa.gov

- E-mail your question via the Internet to help@sti.nasa.gov

- Fax your question to the NASA Access Help Desk at 301-621-0134

- Telephone the NASA Access Help Desk at $301-621-0390$

- Write to: NASA Access Help Desk NASA Center for AeroSpace Information 7121 Standard Drive Hanover, MD 21076 
NASA/TM-2001-211096

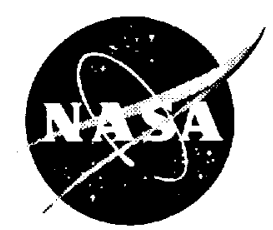

\title{
Pressure Probe Designs for Dynamic Pressure Measurements in a Supersonic Flow Field
}

\author{
A. Robert Porro \\ Glenn Research Center, Cleveland, Ohio
}

Prepared for the

19 th International Congress on Instrumentation in Aerospace Simulation Facilities (ICIASF) 2001) sponsored by the Institute of Electrical and Electronics Engineers, Aerospace and Electronic Systems Society

Cleveland, Ohio, August 27-30, 2001

National Aeronautics and

Space Administration

Glenn Research Center 
Available from

NASA Center for Aerospace Information 7121 Standard Drive

Hanover, MD 21076
National Technical Information Service 5285 Port Royal Road Springfield, VA 22100

Available electronically at http://gltrs.grc.nasa.gov/GLTRS 


\title{
PRESSURE PROBE DESIGNS FOR DYNAMIC PRESSURE MEASUREMENTS IN A SUPERSONIC FLOW FIELD
}

\author{
A. Robert Porro \\ National Aeronautics and Space Administration \\ Glenn Research Center \\ Cleveland, Ohio 44135
}

\begin{abstract}
A series of dynamic flow field pressure probes were developed for use in large-scale supersonic wind tunnels at NASA Glenn Research Center. These flow field probes include pitot, static, and five-hole conical pressure probes that are capable of capturing fast acting flow field pressure transients that occur on a millisecond time scale. The pitot and static probes can be used to determine local Mach number time histories during a transient event. The five-hole conical pressure probes are used primarily to determine local flow angularity, but can also determine local Mach number. These probes were designed, developed, and tested at the NASA Glenn Research Center. They were also used in a NASA Glenn 10- by 10-Foot Supersonic Wind Tunnel (SWT) test program where they successfully acquired flow field pressure data in the vicinity of a propulsion system during an engine compressor stall and inlet unstart transient event. Details of the design, development, and subsequent use of these probes are discussed in this report.
\end{abstract}

\section{INTRODUCTION}

Current trends in supersonic propulsion research tend to focus more on analyzing transient fluid flow phenomena. Steady-state data, while valuable and informative, may not give a true characterization of the flow field in question. What may appear to be a benign steady-state flow may have some undesirable transient characteristics that do not come to light due to the time averaged nature of steady-state data acquisition. In the case of supersonic propulsion systems, recent analysis show that the instantaneous dynamic flow distortion at the inlet/engine interface plane is a more reliable predictor of impending engine compressor surge and stall rather than the steady-state flow distortion. Also, fast acting transients, such as an inlet unstart and subsequent engine compressor stall, occur on a millisecond time scale and cannot be adequately characterized with steady-state instrumentation.

Researchers at NASA Glenn Research Center had a unique challenge in this arena of data acquisition:
Characterize the flow field in the vicinity of a supersonic propulsion system during an engine compressor stall and subsequent inlet unstart. Relevant parameters such as flow field static and pitot pressure, Mach number, and flow angularity needed to be determined to properly characterize the surrounding flow field during a stall/unstart transient that lasts less than 40 milliseconds. Dynamic pitot and static pressure probes were developed to acquire the transient flow field pressure data and were used to determine local transient Mach number; a dynamic five-hole conical pressure probe was developed to determine the local transient flow angle. Large strut assemblies called instrumentation struts were used as a mounting platform to locate the instrumentation in the flow field in the vicinity of the propulsion system. This report will focus on the design and development of these probes. Limited flow field data acquired by these probes during a propulsion system compressor stall/inlet unstart event are also presented.

\section{SYMBOLS}

$\begin{array}{ll}\mathrm{C}_{\mathrm{p}} & \text { pressure coefficient } \\ \mathrm{D} & \text { probe diameter, in }(\mathrm{mm}) \\ \mathrm{f} & \text { frequency, } \mathrm{Hz} \\ \mathrm{M} & \text { Mach number } \\ \mathrm{P} & \text { pressure, psia } \\ \mathrm{q} & \text { dynamic pressure, psi } \\ \alpha & \text { flow pitch angle, degrees } \\ \beta & \text { flow yaw angle, degrees } \\ \Delta \mathrm{M} & \text { change in Mach number }\left(\mathrm{M}-\mathrm{M}_{\mathrm{o}}\right) \\ \tau & \text { frequency time constant }\end{array}$

Subscripts:

o free stream condition

ref reference condition

$s$ refers to static pressure

$x \quad$ five-hole conical probe port number

1 condition when pressure rise begins in shock tube

2 condition when pressure rise reaches plateau in shock tube 


\section{FLOW FIELD PRESSURE PROBE}

\section{DEVELOPMENT}

\section{Pitot and Static Probe}

\section{Design}

A photograph of the flow field pressure probe is shown in Figure 1. The probe design contains four major components: (a) Static pressure aerodynamic tip, (b) Pressure-sensing cartridge assembly, (c) Pitot pressure aerodynamic tip, and (d) Mounting stem. This modular design allows for a variety of probe tips to be used for a specific application. Here, the focus is flow field pressure measurements in supersonic flows, so we developed a cone-cylinder static pressure tip and a pitot pressure tip. Alternatively, probe tips optimized for subsonic and transonic flows could be used with this design. The probe diameter used in this investigation is 0.435 in $(11.05 \mathrm{~mm})$. A detailed discussion of this probe design can be found in Reference 1 .

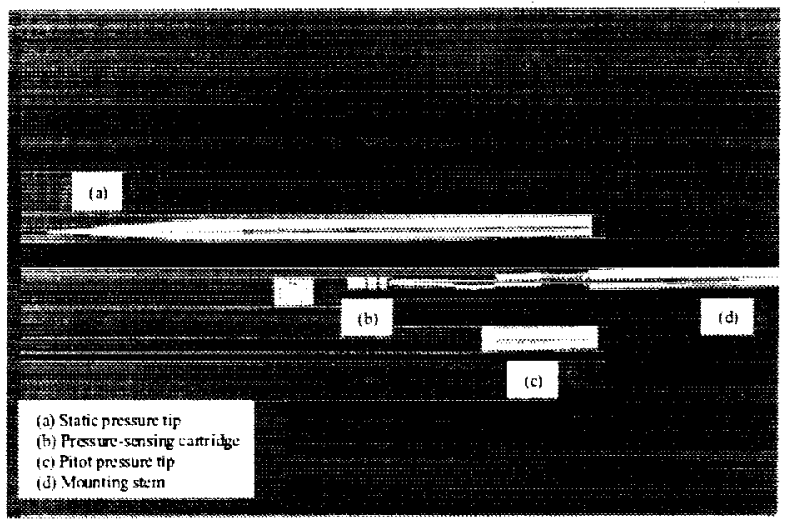

Figure 1. Flow field pressure probe components.

A schematic of the static pressure probe tip is shown in Figure 2. The external aerodynamic configuration is a conventional supersonic cone-cylinder design with a 10 degree included angle cone followed by a constant diameter cylinder. Eight static pressure ports are spaced at equal circumferential distances 10 diameters downstream of the cone shoulder. Reference 2 indicates that this design gives accurate flow field static pressure measurements, and we substantiate this aerodynamic design by our own development testing which is reported later.

The pitot pressure tip is a constant diameter cylinder tip design with a 20 degree chamfered leading edge internal flow passage. It is a traditional design, and Reference 3 reports that this design will give accurate pitot pressure measurements with less than 1 percent deviation from true pitot pressure in flow fields with flow angularity of up to 30 degrees.

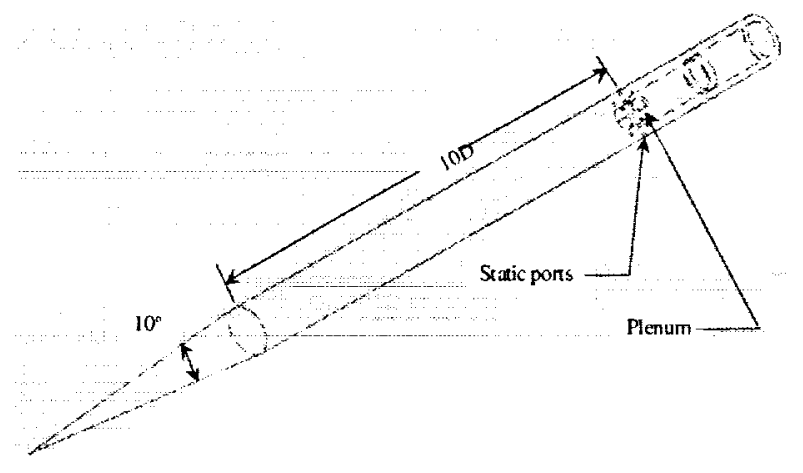

Figure 2. Sketch of static pressure probe tip.

Each tip has a built-in plenum that serves as a pressure measurement chamber when the probe is assembled. The schematic in Figure 2 shows this detail for the static pressure tip. The plenum of the pitot pressure tip is formed by terminating the internal flow passage to form a perforated wall. This design feature protects the high response pressure transducer from debris impact damage. The plenum volumes are optimized for system frequency response and measurement accuracy. In this study, the nominal plenum volumes for the static and pitot tip are $5.67 \times 10^{-3} \mathrm{in}^{3}\left(0.093 \mathrm{~cm}^{3}\right)$ and $6.80 \times 10^{-3} \mathrm{in}^{3}\left(0.111 \mathrm{~cm}^{3}\right)$, respectively.

The pressure sensing mechanism in this probe design is a unique cartridge assembly that simultaneously senses steady-state and transient pressure. This allows accurate dynamic pressure measurements during a transient event because the steady-state pressure measurement can be used to correct for dynamic transducer calibration zero shift that can occur during a wind tunnel test run. A close-up frontal view of the cartridge is shown in Figure 3a. The steady-state pressure is measured via four pneumatic flow passages on the periphery of the cartridge that feeds into a plenum. Pneumatic tubing connects this plenum to a steady-state electronically-scanned pressure transducer that provides the steady-state pressure measurement. The transient pressure is measured directly by a high response transducer mounted in the center of the cartridge as shown in Figure 3a. When the probe is assembled, its measurement diaphragm is flush with the rear of the pressure measurement plenum. In this investigation, we use miniature, temperature-compensated, piezoresistive pressure transducers with a nominal frequency response of $225 \mathrm{kHz}$. The nominal diameter of the transducer assembly is 0.062 inch $(1.57 \mathrm{~mm})$. A double o-ring design on the outer circumference of the cartridge as shown in Figure $3 \mathrm{~b}$ provides a pneumatic seal when the assembly is inserted in the probe mounting stem. 

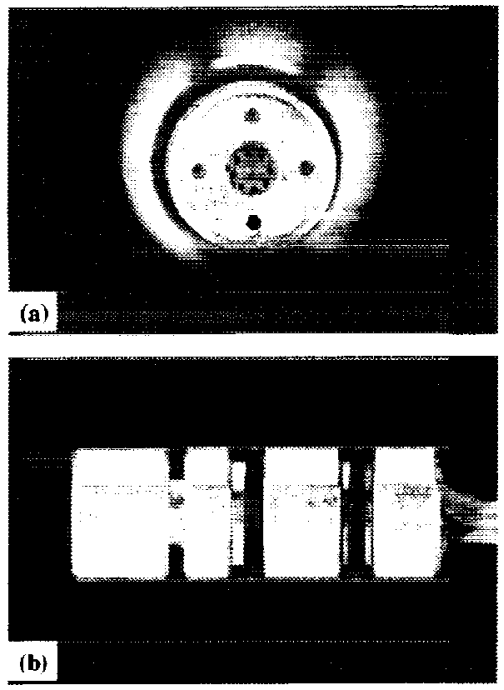

( a ) Front view

(b) Side view

Figure 3. Flow field probe pressure-sensing cartridge.

The probe mounting stem provides an interface between the aerodynamic measurement tip and facility mounting hardware. A fine-pitched thread design secures the aerodynamic tip to the mounting stem. In addition, it has a chamber to hold the pressure sensing cartridge assembly. The probe mounting stem can be designed to interface with a variety of wind tunnel hardware. The critical integration factor is that the probe stem and mounting hardware must be designed to minimize interference with flow field static pressure measurements. For the recent 10 - by 10 -Foot SWT test program, these probes are integrated into an instrumentation strut that uses a 10 degree included angle wedge leading edge design. The probe mounting stem used in this investigation is a constant diameter cylindrical design of sufficient length to integrate into the instrumentation strut design. Design principles discussed in Reference 4 are used to choose the probe stem length and instrumentation strut leading edge angle.

\section{Development Testing}

The development of these transient flow field pitot and static pressure probes required some proof of concept testing. Two series of tests were conducted to validate the concept: (1) Steady-state testing in a small supersonic wind tunnel, and (2) Transient testing in a small shock tube facility. The steady-state testing validated the probe's aerodynamic design and verified that the time-averaged component of the transient pressure signal matched the steady-state pneumatic pressure measurement. Transient testing was used to characterize the probe's frequency response.

Steady-state testing. - The objective of the steadystate probe testing was to assure that the probe design was sound and actually measured the flow ficld static or pitot pressure. A typical result from this portion of the development testing is shown in Figure 4. The figure shows simultaneous static pressure measurements acquired by the probe's steady-state and dynamic transducers. The static pressure data were normalized by the actual tunnel static pressure measured by surface-mounted pressure ports in the wind tunnel test section. The band about the time-averaged dynamic data corresponds to a \pm 1.25 percent pressure measurement differential which was the resolution of the dynamic pressure measurements $( \pm 0.01$ psi or $68.95 \mathrm{~Pa}$ ). There is good agreement between the timeaveraged dynamic and steady-state transducer pressure measurements. These results indicate that the simultaneous pressure measurement capability incorporated in this probe design does not compromise its measurement accuracy. In addition, the plot in Figure 4 shows that the static pressure probe measured the true static pressure within a two percent margin from pitch angle of -5 degrees to +3 degrees. This result was typical of the pitch angle tolerance that we saw at other Mach numbers.

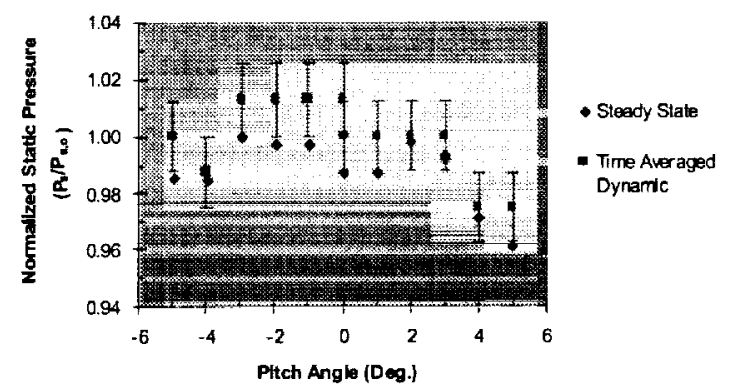

Figure 4. Steady-state flow field static pressure response at Mach 2.5.

Transient testing.--The objective of the transient probe testing was to characterize and optimize the static pressure probe's frequency response. The prototype static pressure probe had an oversized pressure measurement plenum whose volume was optimized for frequency response during this series of tests.

We determined the frequency response of a series of dynamic static pressure probes in a shock tube facility. 
The moving normal shock wave produced a step change in static pressure as the shock wave passed over the probe's measuring station. The frequency response of the probe due to the step change in static pressure could be characterized by a first order system response to a step input:

$$
f=\frac{1}{2 \pi \tau}
$$

where $\tau$ is a time constant determined by the following procedure:

1) Determine the equivalent pressure step amplitude response which is

$$
P_{\tau}=P_{1}+0.632 \cdot\left(P_{2}-P_{1}\right) \text {. }
$$

Station 1 is at time when shock wave first influences static pressure.

Station 2 is at time when static pressure rise reaches plateau after shock wave passes.

2) Determine which time $\left(t_{\tau}\right)$ corresponds to this amplitude response.

3) Determine time constant from the following: $\tau=\mathrm{t}_{\tau}-\mathrm{t}_{\mathrm{l}}$.

The transient response of the static pressure probe was compared to a dynamic pressure transducer that was flush-mounted on the shock tube wall at the same axial station. The wall-mounted transducer ideally measured the true static pressure in the shock tube. The shock tube results confirmed that the flow field static pressure measured by the probe did indeed agree with the static pressure indicated by the wall-mounted static pressure port. A pair of static pressure traces acquired in the shock tube is shown in Figure 5. Figure 5a shows the overall response while Figure 5 b shows the initial shock response and the relevant frequency determination parameters. The solid line represents the pressure trace of the wall-mounted transducer while the dashed line indicates the pressure trace of the transducer installed in the flow field static pressure probe.

The primary test article was the dynamic static pressure probe. Two variations of the static pressure probe were tested. The first probe was constructed of brass and was a prototype design that had an oversized intemal pressure measurement plenum whose volume was $0.02835 \mathrm{in}^{3}\left(0.465 \mathrm{~cm}^{3}\right)$. We varied the size of this plenum to optimize the probe's frequency response. The second static pressure probe was constructed of aluminum and contained a fixed internal volume which was 20 percent of the prototype probe's total internal volume. Table 1 shows the results of this parametric testing.
The first configuration tested was the 50 percent volume case. This means that only 50 percent of the available plenum volume was used. The testing results indicate that the probe's dynamic frequency response was about $300 \mathrm{~Hz}$ with this plenum size. We further reduced the plenum volume to 20 percent and then to 12 percent in the prototype probe. We noticed a significant improvement by reducing the plenum volume to 20 percent $(936 \mathrm{Vs} 302 \mathrm{~Hz})$. However, as we reduced the volume to its minimum size, we noticed no significant improvement over the 20 percent results.
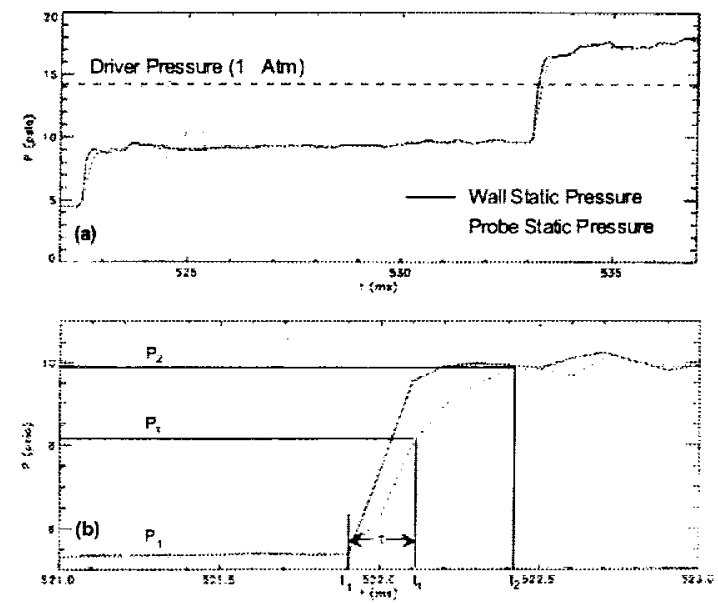

(a) Overall response.

\section{(b) Close-up showing relevant parameters.}

Figure 5. Transient pressure response in shock tube.

Next, we tested the aluminum probe with the fixed internal volume that was equivalent to the 20 percent volume configuration of the prototype probe. We conducted multiple test runs of this configuration to better assess the probe's frequency response. We felt that this was necessary because (1) the shock tube may not fire in the exact same manner every time which could introduce some uncertainty, and (2) we determined the frequency response with graphical techniques which also could introduce some uncertainty in the frequency response calculation. The average frequency response for four separate test runs was $812 \mathrm{~Hz}$ for this probe. Three of the firings yielded similar results while the number two firing yielded a somewhat lower frequency response. For the number one and two firings, the steady pressure sensing port was inadvertently left open to atmospheric pressure, while it was sealed during the number three and four firings. As shown in the results, the atmospheric pressure tended to reduce the frequency response of the 
probe due to the possible inflow of higher pressure air into the plenum of the probe. However, we noticed no adverse effects of this inflow on the accuracy of the static pressure measurement.

Table 1. TRANSIENT TESTING RESULTS

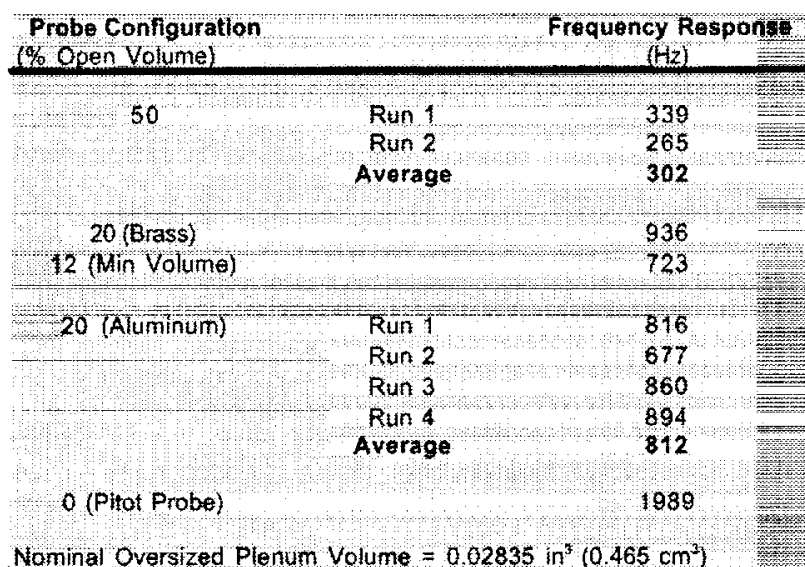

\section{Five-Hole Conical Probe}

\section{Design}

A schematic and photographs of the supersonic fivehole conical probe design are shown in Figures 6 through 8 . The probe diameter is 0.25 inch $(6.35 \mathrm{~mm})$. The probe tip is threaded and could be removed from the stem. This design feature is used because the calibration hardware could not accommodate the long probe stem, and it simplifies the transducer installation. The probe tip peripheral ports are cut back at a 30 degree angle to form a 60 degree included angle cone. The center port measures pitot pressure, while the cut back ports on the periphery measure a combination of static and pitot pressure. The probe diameter, 0.25 inch $(6.35 \mathrm{~mm})$, is the minimum dimension that could accept three adjacent 0.062 inch $(1.57 \mathrm{~mm})$ high response transducers similar to the ones used in the static and pitot pressure probe cartridge. To maximize frequency response, these dynamic transducers are mounted in the probe tip passages. Metal

0.25 in
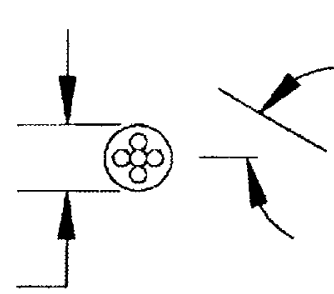
$30^{\circ}$

\section{$(6.35 \mathrm{~mm})$}

Figure 6. Schematic of five-hole conical probe.

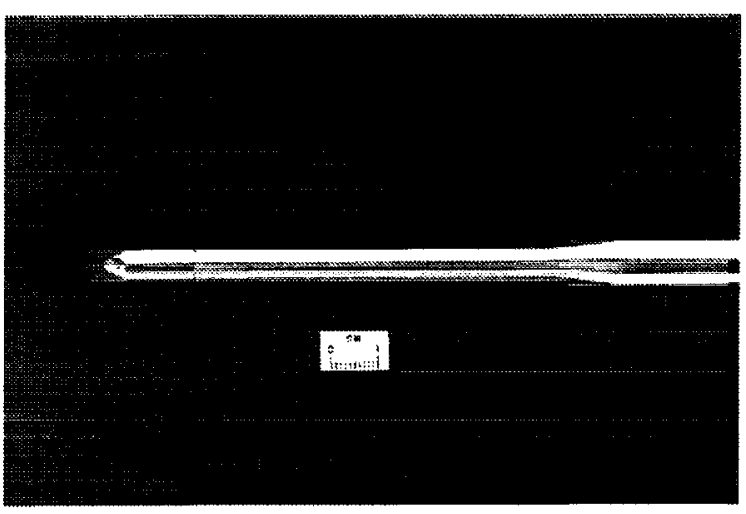

Figure 7. Side view of five-hole conical probe.

shields are installed upstream in the passages to protect the transducers from debris impact. A frontal view of the probe is shown in Figure 8 . This compact design precludes the inclusion of pneumatic flow passages to simultaneously measure the steady-state pressure as is done with the pitot and static probes. Therefore, the five-hole conical pressure data cannot be corrected for offset measurement errors that occur during the course of a wind tunnel test run.

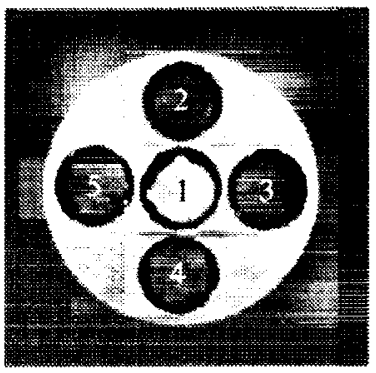

Figure 8. Front view of five-hole conical probe.

\section{Calibration}

The pressure data needed for calibration were acquired in the NASA Glenn Research Center 1- by 1-Foot Supersonic Wind Tunnel (SWT). The calibration method related these pressure measurements to a pitch angle, yaw angle, and Mach number. We used the methodology developed in Reference 5 to implement the data reduction of discrete pressure measurements to reduced flow angularity and Mach number by using the calibration data. Each probe must be individually calibrated because of geometric differences that arise during the manufacturing process. Steady-state pressure data can be used for the calibration, so we did not install the dynamic transducers during the calibration wind tunnel runs. However, the transducer 
shields were installed, and we used temporary pneumatic tubing that mated to our steady-state pressure measurement system. For each Mach number, pressure data were acquired at 2.5 degree increments in the yaw and pitch intervals. The five-hole pressure probes were calibrated at discrete Mach numbers of 1.6, $2.0,2.5$, and 2.8 and $a$ pitch and yaw angle range of \pm 15 degrees. This resulted in acquiring 169 data points per Mach number and 676 data points total for each probe. Assuming a conservative estimate of 30 seconds of tunnel running per data point, this required $5.6 \mathrm{hr}$ of tunnel run time per probe. A typical plot of calibration data in reduced variables is shown in Figure 9.

The calibration parameters are defined as follows:

Pitch and yaw angle pressure coefficients,

$$
c_{p, \text { pirch }}=\frac{P_{2}-P_{4}}{q}, \quad c_{p}, \text { law }=\frac{P_{3}-P_{5}}{q},
$$

where $\mathrm{P}_{\mathrm{x}}$ is a probe peripheral pressure as defined in Figure 8 , and $\mathrm{q}$ is the local dynamic pressure. When these probes are used in an actual test program, Ports 2 and 4 are aligned with the pitch axis while ports 3 and 5 are aligned with the yaw axis.

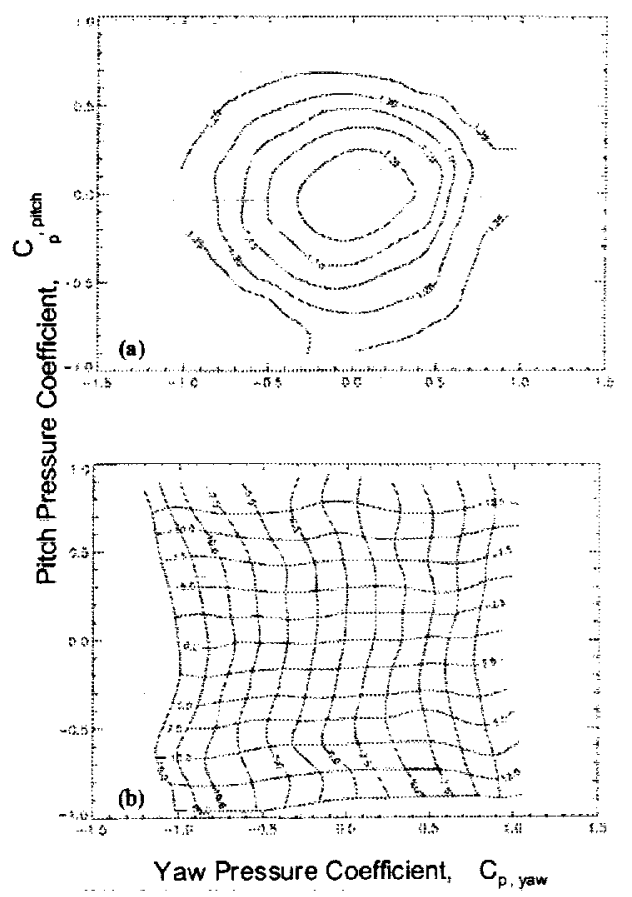

(a) Pitot pressure correction.

(b) Flow angle calibration.

Figure 9. Typical probe calibration data set, $\mathbf{M}_{\mathbf{0}}=\mathbf{2 . 8}$.
In the test program, we were able to determine the instantaneous local flow pitch $(\alpha)$ and yaw $(\beta)$ angle during a propulsion system unstart/stall event by using the five dynamic pressure time histories and the calibration method described in references 5 and 6 . An artifact of the calibration procedure was that local instantaneous Mach number could also be determined along with the local flow angle. However, the main limitation with these probes was that any indicated results that fell out of the calibration range werc suspect. Therefore, any results indicating a flow angle greater than +15 degrees or less than -15 degrees were not valid. Similarly, calculated Mach numbers less than 1.6 or greater than 2.8 were suspect.

\section{APPLICATION IN WIND TUNNEL TEST}

These dynamic probes werc used in a NASA Glenn 10- by 10-Foot Supersonic Wind Tunnel (SWT) test program to acquire transient flow field pressure data in the vicinity of a supersonic propulsion system during an engine compressor stall and subsequent inlet unstart event. The tunnel was run in the propulsion cycle mode at ambient conditions. Details of this unique mode of operation are given in reference 7 . A two-dimensional bifurcated inlet mated to a turbojet engine mounted beneath a large flat plate simulated an under wing supersonic propulsion pod installation. A photograph of the experimental hardware installation is shown in Figure 10.

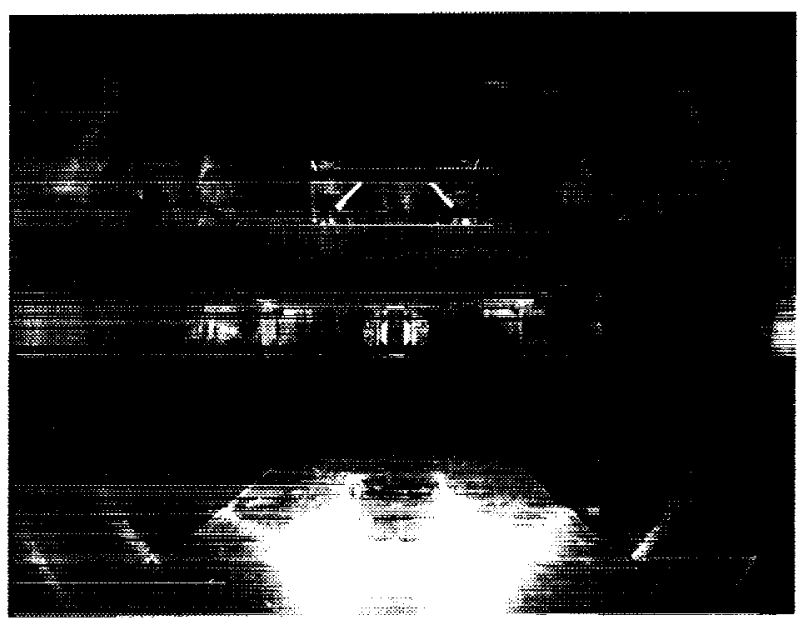

Figure 10. Inlet unstart experiment hardware installation in 10- by 10- foot SWT.

The bulk of the transient flow field data are acquired by pressure instrumentation mounted on platforms that we call instrumentation struts. These instrumentation struts are versatile in the respect that each port can be fitted with a pitot, static, or flow angularity probe. A photograph of these struts attached to the wing simulator is shown in Figure 11. The struts are 60 inch 
$(152.4 \mathrm{~cm})$ long and offer us the ability to instrument a significant portion of the flow field in the vicinity of the propulsion system. The leading edge of each strut is a 10 degree included angle wedge of sufficient length to minimize interference with the flow field static pressure probe measurements. In addition, the shallow wedge angle insures that the shock emanating from the strut leading edge does not interfere with the flow field of interest in the vicinity of the propulsion system.

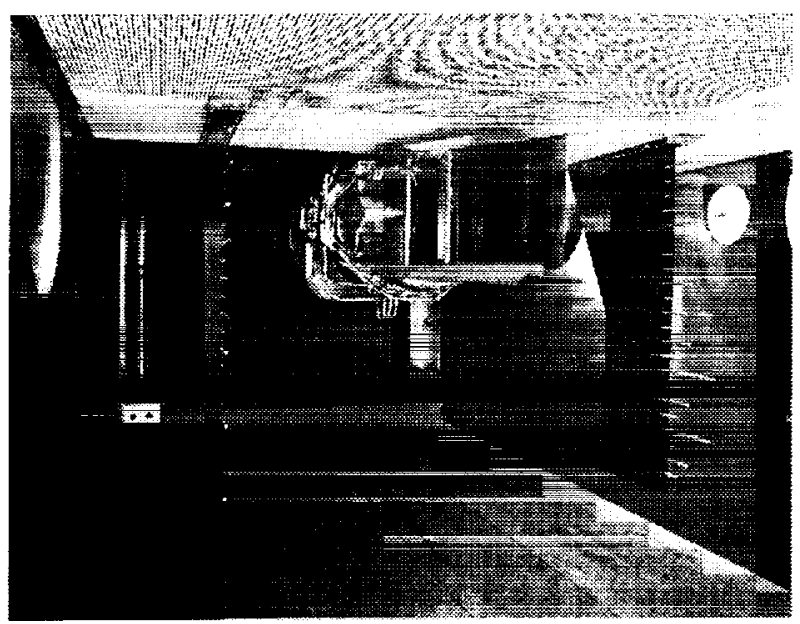

Figure 11. Inlet unstart experiment hardware installation with instrumentation struts.

The instrumentation configuration shown in Figure 12 is optimized to acquire transient Mach number and flow angularity data. It is instrumented with alternating pitot and static pressure probes, while other configurations use all pitot or all static probes. A five-hole conical pressure probe is substituted for a pitot probe. The pressure port spacing on the instrumentation strut is 2.5 inch $(6.35 \mathrm{~cm})$ which can be used for an all pitot pressure probe configuration. However, when using static pressure probes, a 5 inch $(12.7 \mathrm{~cm})$ spacing is required due to aerodynamic interference effects. The short conical probes shown in the figure are dummy probes that do not acquire data when using the 5 inch $(12.7 \mathrm{~cm})$ probe spacing.

\section{Pitot and Static Probe}

For this particular test program, the primary use of the alternating pitot-static pressure probe measurements was to determine the local Mach number in the flow field region affected during a propulsion system unstart/stall transient event. For a known local pitot and static pressure, we used the Rayleigh pitot formula (equation 100 in reference 8 ) to determine the local Mach number. Figure 13 shows the results of using this approach for two pitot pressure probes evenly spaced about a static pressure probe. The transient pressure

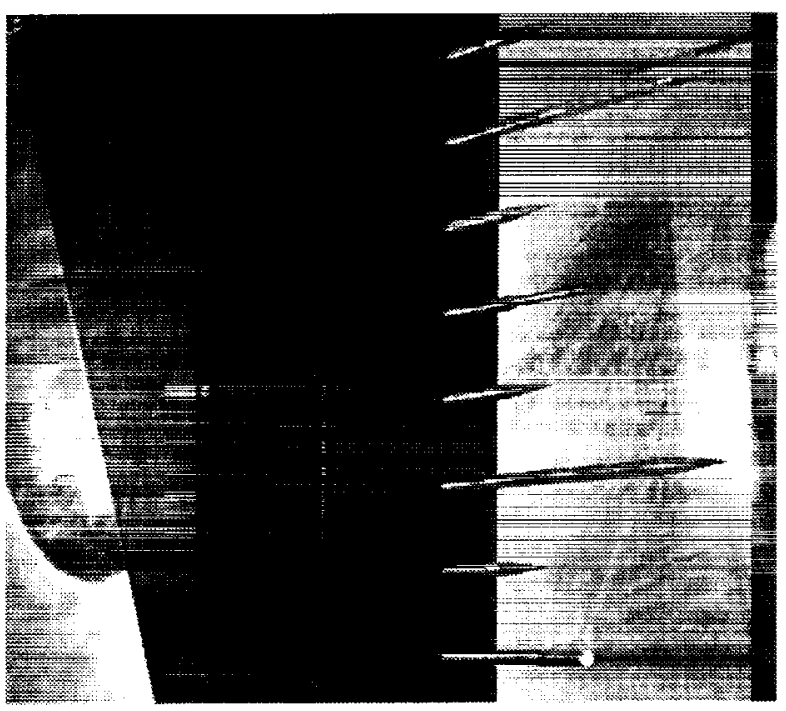

Figure 12. Close-up view of installed instrumentation.

data were corrected for offset errors by using the pneumatic steady-state pressure reading just before the transient event occurs. This approach gave an accurate Mach number calculation.

The upper plot uses the pitot pressure probe closest to the wing simulator flow surface and the adjacent static pressure probe to determine the local Mach number distribution during a stall/unstart transient. We see that the local pitot pressurc value immediately drops to the static pressure value during the transient. This is a classic indication of boundary layer flow separation on the wing simulator surface. The corresponding Mach number is subsonic and shows a 78 percent loss relative to the undisturbed supersonic free stream Mach number during the transient.

The lower plot shows a local flow field Mach number calculation using the same static pressure probe, but the next adjacent pitot pressure probe. The flow remains supersonic in this region, but experiences a 23 percent loss in Mach number during the transient. Note that the entire transient has occurred in a $30 \mathrm{~ms}$ time span, and these probes did capture the transient flow field phenomenon in enough detail to discern the flow physics.

This method of determining local flow field Mach number uses a discrete static and pitot pressure measurement and the Rayleigh pitot formula to calculate the local Mach number. The main limitation with this technique is that the physical distance between the probes introduces spatial resolution errors due to probe response time lag, disturbance propagation 

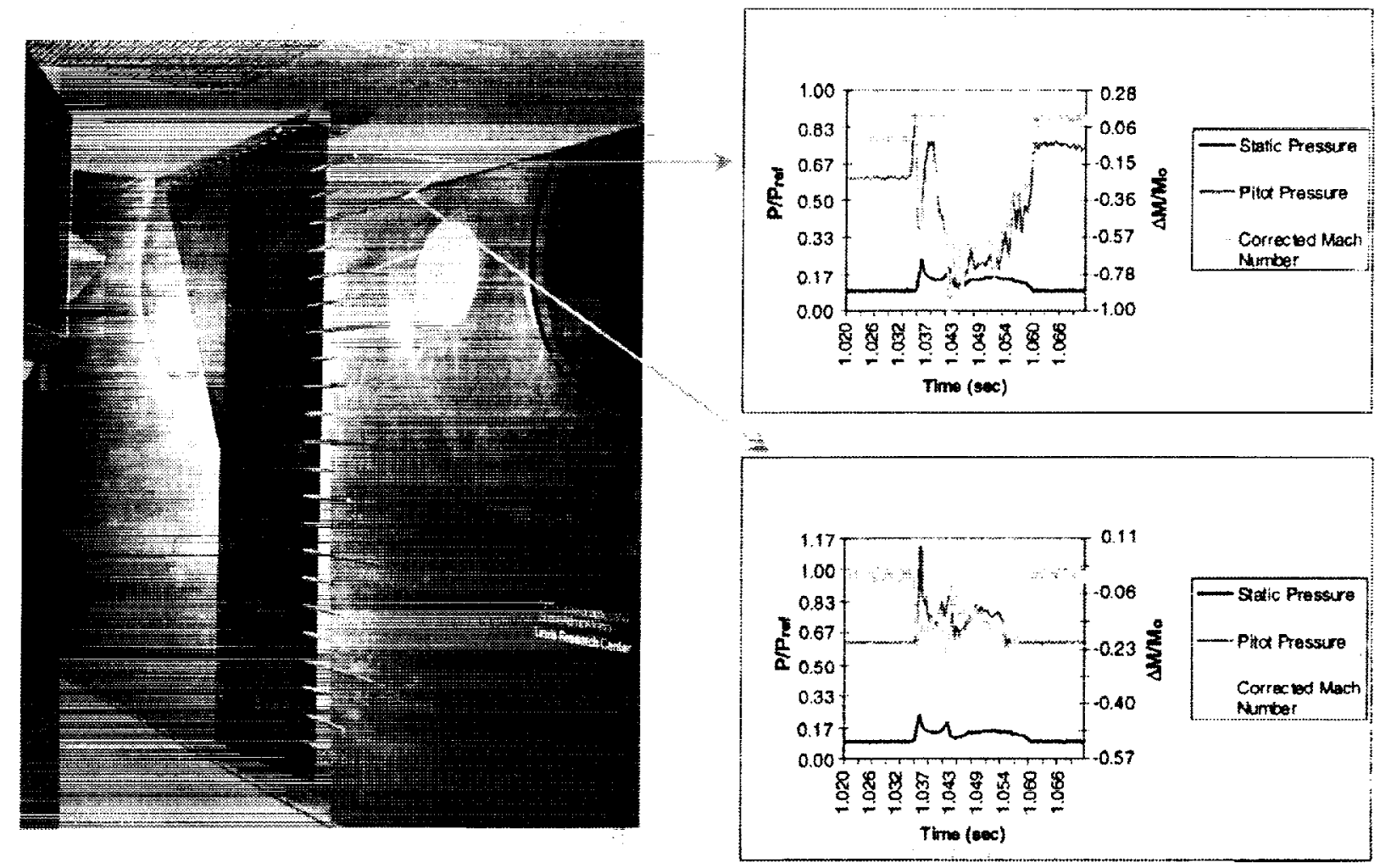

Figure 13. Local transient Mach number determined by flow field pressure measurements.

effects, and the assumption that the measured static pressure is constant over the 5 in $(12.7 \mathrm{~cm})$ region between the static and pitot pressure measurement location. In addition, high local flow angles can cause the static pressure measured by cone-cylinder static pressure probe to be incorrect. Our development testing of these probes shows that the cone-cylinder static pressure probes are accurate to I percent of true static pressure when the local flow angle is less than 4 degrees. When flow angles exceed four degrees, the indicated static pressure is lower than the true flow field static pressure. However, there are some advantages by using this technique to determine transient flow field Mach number: (1) The probe acquires steady-state and transient pressure data simultaneously, so the transient data can be corrected for zero shift to yield accurate pressure distributions during the unstart/stall event; and (2) No extensive calibration is required to determinethe local flow field Mach number.

\section{Five-Hole Conical Probe}

The five-hole pressure probes were used in the same NASA Glenn 10- by 10-Foot Supersonic Wind Tunnel (SWT) test program that acquired transient flow field pressure data in the vicinity of a supersonic propulsion system during a engine compressor stall and subsequent inlet unstart event. The probe pressure data were used with the calibration to determine local flow field angularity and Mach number.

The data shown in Figure 14 are reduced data from a five-hole conical probe that captured a hammershock propagating through the flow field in the vicinity of a propulsion system during a propulsion system stall/unstart transient event. These particular plots show the axial propagation effects of the disturbance at two axial planes upstream of the propulsion system. Figure 14a depicts the pitch angle response during the transient event. At each axial station, the initial transient exceeds the calibration limit of -15 degrees, but settles out to a relatively constant pitch angle during the disturbance until recovering to the undisturbed initial flow angle at the end of the transient.

The yaw angle response during the unstart transient is shown in Figure 14b. At the downstream axial plane, the initial transient exceeds the calibration limit of +15 degrees. The high initial yaw angle is not seen at the upstream axial location. For the rest of the transient, the yaw angles are relatively constant and are much lower in magnitude than the observed pitch angles. 
The local transient Mach number time history obtained from each five-hole probe are shown in Figure $14 \mathrm{c}$. The transient Mach number data should not be considered for analysis at the beginning of each transient where the pitch and yaw angle exceeds the calibration limits. At the downstream axial plane the Mach number distribution during the transient is well behaved, and the upstream Mach number time history shows a plateau region of reduced Mach number before the flow field recovers to free stream conditions.

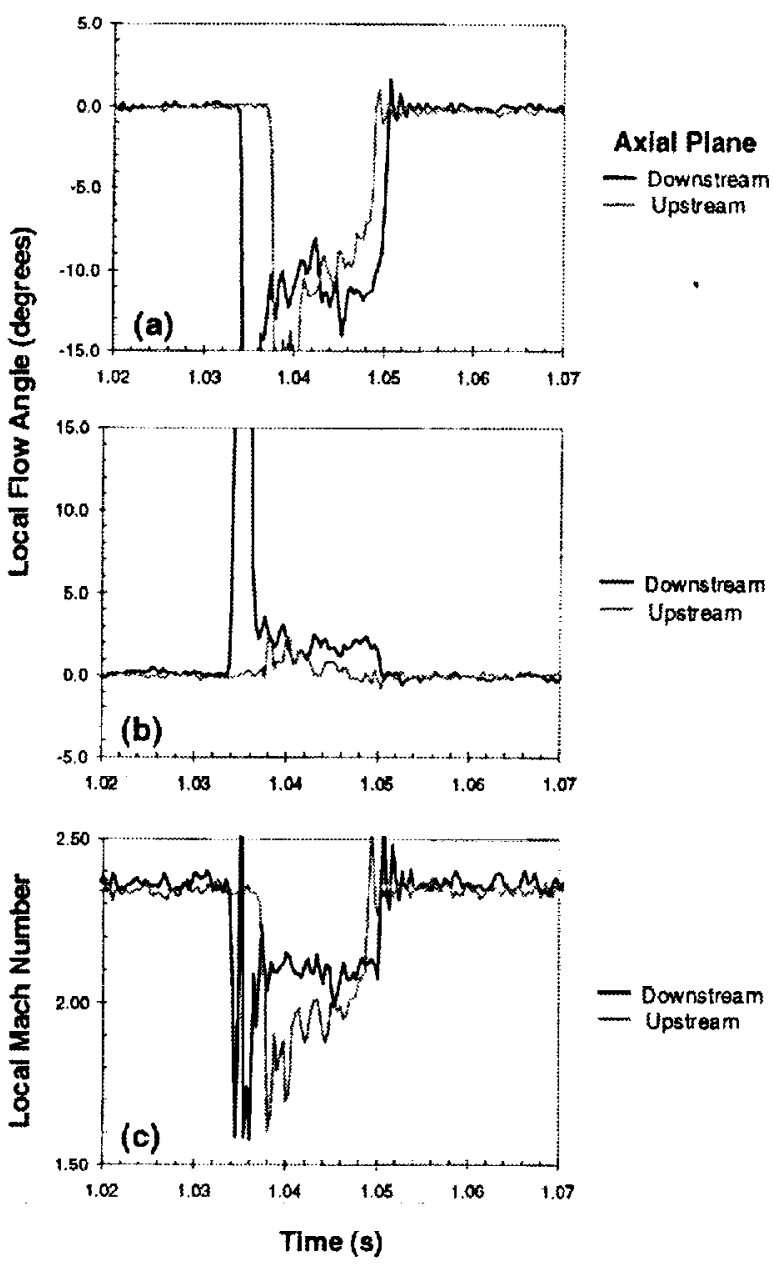

(a) Local pitch angle, $\alpha$

(b) Local yaw angle, $\beta$

(c) Mach number.

\section{Figure 14. Flow angle and Mach number transients during unstart event.}

When used for determination of local flow field Mach number, the five-hole pressure flow angularity probes have a distinct advantage over the isolated static and pitot pressure measurement technique. Spatial resolution effects discussed earlier with the isolated pitot and static probe technique are minimized since all pressure measurements are acquired simultaneously at essentially the same measurement location. However, the main limitation of this approach is that a fairly extensive calibration data set for each probe must be acquired. The calibration facility run time to acquire these calibration data could be cost prohibitive. Also, another limitation is that reduced data that fall outside of the calibration range are suspect and should not be used. When using these probes for transient data acquisition, five high response transducers are installed such that the sensing surface is near the probe tip. The compact probe size does not allow for the inclusion of steady-state pressure measurement, so the transient pressure readings cannot be corrected for zero offset errors. From an operational standpoint, if one transducer fails during the test run, the data from that particular five-hole probe is not usable for analysis.

Figure 15 compares the Mach number obtained at the same location with the five-hole probe versus the Mach number calculated by using the alternating pitot and static probes. The data are acquired during the same transient depicted in Figure 14. For alternating pitot and static probes, the center port of the five-hole probe is used as the local pitot pressure. The Mach numbers calculated by the two techniques shown in Figure 15a agree favorably at the downstream location. The Mach number comparison at the upstream axial plane shown in Figure $15 \mathrm{~b}$ is not as favorable. The data trends are similar, but the five-hole pressure probe results predict a lower average value in the region between the starting and ending transients.

The five-hole pressure probe best captures the duration of the transient event due to its superior spatial resolution. However, the Mach number calculation at the beginning and end points of the transient are suspect - the beginning transient is suspect due to the calculated flow angles exceeding calibration limits, and the ending transient shows some artificial oscillations that are seen in the pressure data. These apparent oscillations could be due to the data acquisition and digitization not accurately capturing the step change in pressure. The alternating pitot and static probe data also misrepresent the Mach number trends at the beginning and end of the transient event. The spatial resolution issue with this technique causes the initial transient to occur earlier and the ending transient appears to be smeared over a $4 \mathrm{~ms}$ interval. However, it is interesting to note that the five-hole probe results also do not predict an accurate Mach number in this region, and both techniques show the return to the free stream Mach number at about the same time. 


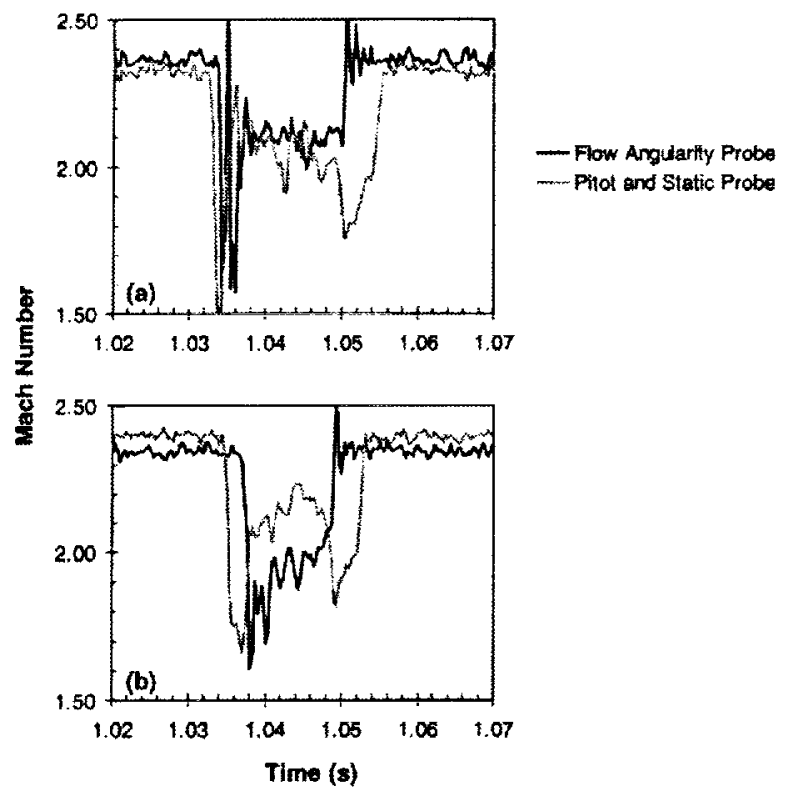

(a) Downstream axial plane.

(b) Upstream axial plane.

Figure 15. Comparison of flow angularity probe versus pitot and static probe flow field Mach number calculation.

\section{CONCLUDING REMARKS}

We discussed the design and development details of pressure probes suitable for capturing the dynamics of fast acting transients in a supersonic flow field. Flow field pitot, static, and five-hole conical probes were developed. The pitot and static probes had conventional exterior aerodynamic contours, but used a novel internal plenum and pressure measurement cartridge assembly to simultaneously measure the steady-statc and dynamic flow field pressure. In addition to providing flow field pressure data, the pressure data from these probes could also be used to determine local flow field Mach number variation during a transient. The five-hole conical probes were also designed to measure fast acting transients by installing dynamic transducers in each of the pressure ports. The pressure data from these probes were used to determine instantaneous flow angles and local Mach numbers. An extensive calibration dataset had to be developed for each five-hole conical probe to relate the raw pressure measurements to flow angle and Mach number.
These probes were used in a wind tunnel test program to successfully capture the flow field dynamics of a supersonic propulsion system compressor stall and inlet unstart transient acting on a $\mathbf{4 0}$ millisecond time scale. The probe measurements did produce time histories of mcasured flow field pressures, flow angles, and local Mach numbers. The pitot and static probes produced accurate transient pressure time histories because the simultaneous measurement of steady-state pressure allowed correction for zero offset errors of the dynamic pressure transducer. The limitations of each technique were discussed. The pitot-static method of determining local Mach numbers introduced spatial measurement errors, while the five-hole conical probe measurements produced invalid flow angles and Mach numbers when the calibration limits were exceeded.

\section{REFERENCES}

1. Porro, A.R.; and Ernst, M.A.: Apparatus for Measuring Ambient Pressure Within a Gaseous Flow Field. U.S. Patent Number 5,756,892, 1998.

2. Pope, A.; and Goin, K.L.: High-Speed Wind Tunnel Testing. Malabar, Florida: Robert E. Kreiger Publishing Company, 1978.

3. Bryer, D.W.; and Pankhurst, R.C.: Pressure-Probe Methods for Determining Wind Speed and Flow. Direction. London: Her Majesty's Stationery Office, 1971.

4. Reed, T.D.; Pope, T.C.; and Cooksey, J.M.: Calibration of Transonic and Supersonic Wind Tunnels. NASA CR-2920, 1977.

5. Naughton, J.W.; Cattafesta III, L.N.; and Settles, G.S.: A Miniature, Fast-Response 5-Hole Probe for Supersonic Flowfield Measurements. AIAA-92-0266, 1992.

6. Centolanzi, F.J.: Characteristics of a $40^{\circ}$ Cone for Measuring Mach Number, Total Pressure, and Flow Angles at Supersonic Speeds. NACA TN-3967, 1957.

7. Soeder, R.H.: User Manual for NASA Lewis 10 - by 10 -Foot Supersonic Wind Tunnel. NASA TM-105626, 1995.

8. Ames Research Center Staff: Equations, Tables, and Charts for Compressible Flow. NACA Report $1135,1953$. 


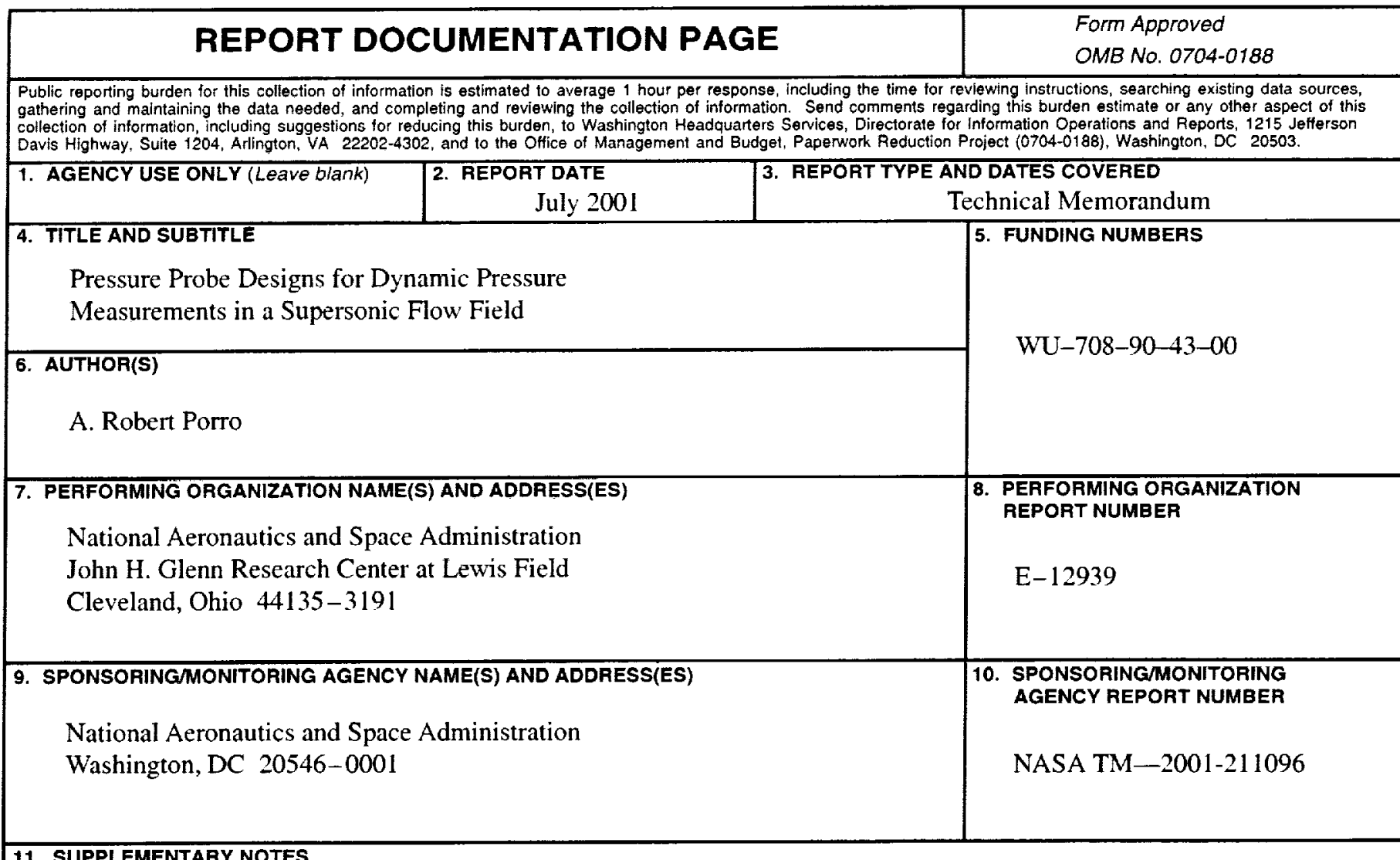

11. SUPPLEMENTARY NOTES

Prepared for the 19th International Congress on Instrumentation in Aerospace Simulation Facilities (ICIASF 2001) sponsored by the Institute of Electrical and Electronics Engineers, Aerospace and Electronic Systems Society, Cleveland, Ohio, August 27-30, 2001. Responsible person, A. Robert Porro, organization code 5850, 216-433-5921.

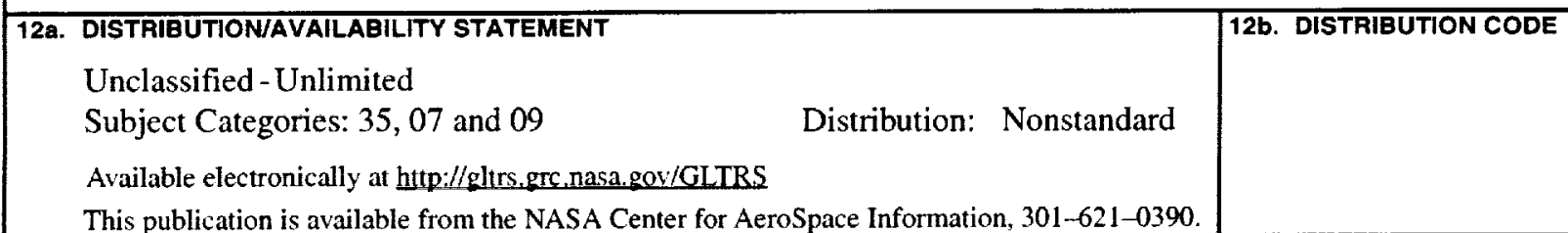

13. ABSTRACT (Maximum 200 words)

A series of dynamic flow field pressure probes were developed for use in large-scale supersonic wind tunnels at NASA Glenn Research Center. These flow field probes include pitot, static, and five-hole conical pressure probes that are capable of capturing fast acting flow field pressure transients that occur on a millisecond time scale. The pitot and static probes can be used to determine local Mach number time histories during a transient event. The five-hole conical pressure probes are used primarily to determine local flow angularity, but can also determine local Mach number. These probes were designed, developed, and tested at the NASA Glenn Research Center. They were also used in a NASA Glenn 10- by 10-Foot Supersonic Wind Tunnel (SWT) test program where they successfully acquired flow field pressure data in the vicinity of a propulsion system during an engine compressor stall and inlet unstart transient event. Details of the design, development, and subsequent use of these probes are discussed in this report.

\begin{tabular}{|c|c|c|c|}
\hline \multirow{2}{*}{\multicolumn{3}{|c|}{$\begin{array}{l}\text { 14. SUBJECT TERMS } \\
\text { Pressure probes; Flow field instrumentation }\end{array}$}} & \multirow{3}{*}{$\begin{array}{l}\text { 15. NUMBER OF PAGES } \\
16 \\
\text { 16. PRICE CODE } \\
\text { 20. LIMITATION OF ABSTRACT }\end{array}$} \\
\hline & & & \\
\hline $\begin{array}{l}\text { 17. SECURITY CLASSIFICATION } \\
\text { OF REPORT } \\
\text { Unclassified }\end{array}$ & $\begin{array}{l}\text { 18. SECUAITY CLASSIFICATION } \\
\text { OF THIS PAGE } \\
\text { Unclassified }\end{array}$ & $\begin{array}{l}\text { 19. SECURITY CLASSIFICATION } \\
\text { OF ABSTRACT } \\
\text { Unclassified }\end{array}$ & \\
\hline NSN 7540-01-280-5500 & & & $\begin{array}{l}\text { Indard Form } 298 \text { (Rev. 2-89) } \\
\text { scribed by ANSI Std. Z39-18 } \\
-102\end{array}$ \\
\hline
\end{tabular}

